Article

\title{
On-Treatment Changes in FIB-4 and 1-Year FIB-4 Values Help Identify Patients with Chronic Hepatitis B Receiving Entecavir Therapy Who Have the Lowest Risk of Hepatocellular Carcinoma
}

\author{
Hung-Wei Wang ${ }^{1}{ }^{\oplus}$, Hsueh-Chou Lai ${ }^{1,2}$, Tsung-Hui $\mathrm{Hu}^{3}$, Wen-Pang $\mathrm{Su}^{1}$, Sheng-Nan $\mathrm{Lu}^{3}$, \\ Chia-Hsin Lin ${ }^{1}$, Chao-Hung Hung ${ }^{3}$, Po-Heng Chuang ${ }^{1}$, Jing-Houng Wang ${ }^{3}$, Mei-Hsuan Lee ${ }^{4}$, \\ Chien-Hung Chen ${ }^{3, *}$ and Cheng-Yuan Peng ${ }^{1,5, *(D)}$ \\ 1 Center for Digestive Medicine, Department of Internal Medicine, China Medical University Hospital, \\ Taichung 404, Taiwan; sdqw190@gmail.com (H.-W.W.); t674233@ms54.hinet.net (H.-C.L.); \\ dadun2022@yahoo.com.tw (W.-P.S.); sk19850121@gmail.com (C.-H.L.); poheng2@yahoo.com.tw (P.-H.C.) \\ 2 School of Chinese Medicine, China Medical University, Taichung 404, Taiwan \\ 3 Division of Hepatogastroenterology, Department of Internal Medicine, College of Medicine, \\ Kaohsiung Chang Gung Memorial Hospital and Chang Gung University, Kaohsiung 833, Taiwan; \\ dr.hu@msa.hinet.net (T.-H.H.); juten@ms17.hinet.net (S.-N.L.); chh4366@yahoo.com.tw (C.-H.H.); \\ jinghoung2001@yahoo.com.tw (J.-H.W.) \\ 4 Institute of Clinical Medicine, National Yang-Ming University, Taipei 112, Taiwan; meihlee@ntu.edu.tw \\ 5 School of Medicine, China Medical University, Taichung 404, Taiwan \\ * Correspondence: e580306@ms31.hinet.net (C.-H.C.); cypeng@mail.cmuh.org.tw (C.-Y.P.); \\ Tel.: +886-4-2205-2121 (ext. 2260) (C.-Y.P.)
}

Received: 19 April 2020; Accepted: 5 May 2020; Published: 7 May 2020

\begin{abstract}
Noninvasive fibrosis indices can help stratify the risk of hepatocellular carcinoma (HCC) in patients with chronic hepatitis $B(\mathrm{CHB})$ receiving nucleos $(\mathrm{t})$ ide analogue $(\mathrm{NA})$ therapy. We investigated the predictive performance of on-treatment changes in FIB-4 $(\triangle$ FIB- 4$)$ and 1-year FIB-4 values (FIB-4 12M) for HCC risk in patients with $\mathrm{CHB}$ receiving entecavir therapy. We included $1325 \mathrm{NA}$-naïve patients with CHB treated with entecavir, retrospectively, from January 2007 to August 2012. A combination of $\triangle$ FIB-4 and FIB-4 $12 \mathrm{M}$ was used to stratify the cumulative risk of HCC into three subgroups each in the noncirrhotic and cirrhotic subgroups with $p<0.0001$ by using the log-rank test (noncirrhotic: the highest risk ( $n=88$ ): FIB-4 $12 \mathrm{M} \geq 1.58 / \triangle \mathrm{FIB}-4 \geq 0$ (hazard ratio (HR): 40.35 ; 95\% confidence interval (CI): 5.107-318.7; $p<0.0001)$ and cirrhotic: the highest risk $(n=89)$ : FIB-4 $12 \mathrm{M}$ $\geq 2.88 / \triangle$ FIB-4 $\geq 0$ (HR: 9.576; 95\% CI: 5.033-18.22; $p<0.0001$ )). Patients with noncirrhotic CHB treated with entecavir who had a FIB-4 $12 \mathrm{M}<1.58$ or FIB-4 $12 \mathrm{M} \geq 1.58 / \triangle$ FIB- $4<0$ exhibited the lowest 5-year HCC risk (0.6\%). A combination of on-treatment changes in FIB-4 and 1-year FIB-4 values may help identify patients with $\mathrm{CHB}$ receiving entecavir therapy with the lowest risk of HCC.
\end{abstract}

Keywords: chronic hepatitis B; entecavir; hepatocellular carcinoma; fibrosis-4 (FIB-4); noninvasive fibrosis index

\section{Introduction}

Liver cirrhosis and hepatocellular carcinoma (HCC) are the major complications of chronic hepatitis B (CHB) [1]. Long-term nucleos(t)ide analogue (NA) therapy leads to the regression of liver fibrosis and cirrhosis and reduces the incidence of HCC [2-5]. Unfortunately, the risk of HCC occurrence remains, although in a recent large cohort of 1951 Caucasian patients with CHB under entecavir or tenofovir treatment, the 8-year survival rate was found to be similar to that for the general 
population [6-8]. The severity of liver fibrosis has been known to be a crucial risk factor for HCC development. Many noninvasive indices or modalities have been utilised instead of liver biopsy to predict liver fibrosis status [9-11]. The aminotransferase-to-platelet ratio index (APRI, Equation (1)) and fibrosis-4 (FIB-4, Equation (2)) index are popular noninvasive indices to predict liver fibrosis in chronic viral hepatitis [12-14]. Furthermore, baseline FIB-4 has a higher predictive performance for HCC than other indices in patients with CHB [15-17]. An Asian study reported that patients with noncirrhotic $\mathrm{CHB}$ receiving long-term NA therapy who had a FIB-4 $<1.29$ at baseline had the lowest risk for HCC [18]. Recent studies in Caucasian patients with CHB revealed that a low platelet count at baseline and liver stiffness measurement $\geq 12 \mathrm{kPa}$ at Year 5 was an independent predictor of HCC development before and after 5 years of entecavir or tenofovir treatment, respectively [19-21]. However, limited reports have addressed how the on-treatment dynamic change or on-treatment value of noninvasive indices affects HCC development. We therefore conducted this study to investigate the risk of HCC according to on-treatment changes in FIB-4 and 1-year FIB-4 values in 1325 NA-naïve patients with $\mathrm{CHB}$ treated with entecavir.

\section{Results}

\subsection{Baseline and On-Treatment Characteristics}

The median age of the study group at baseline was $50 \pm 17$ years. Of the patients, $963(72.7 \%)$ were male, 481 (36.3\%) were cirrhotic, and $158(11.9 \%)$ were diabetic. A total of 105 patients $(7.9 \%)$ developed HCC during a median treatment duration or follow-up period of 4.1 years. The laboratory variables and noninvasive fibrosis indices at baseline and after 1 year of treatment are presented in Table 1. We compared the characteristics of the patients with HCC $(n=105)$ with those without HCC $(n=1220)$. Older age; higher percentages of diabetes mellitus (DM) and cirrhosis; lower serum albumin, aspartate aminotransferase (AST), alanine aminotransferase (ALT), hepatitis B virus (HBV) deoxyribonucleic acid (DNA), and platelet counts; and higher international normalised ratios (INRs), alpha-fetoprotein (AFP), and AFP 12M levels were observed in the patients with HCC (Table 1). Most of the patients with and without HCC had achieved a virological response (VR) after 1 year of entecavir therapy ( $93.3 \%$ and $87 \%$, respectively).

\subsection{APRI, FIB-4, and On-Treatment Changes}

Table 1 shows the APRI and FIB- 4 values at baseline and after 1 year of treatment and presents the on-treatment changes $(12 \mathrm{M}-0 \mathrm{M})$ in all the patients and in the subgroups with and without HCC. Those values at baseline and after 1 year of treatment for the cirrhotic subgroup were $1.22 \pm 1.63$ and $0.69 \pm 0.57$ for APRI, and $3.22 \pm 3.57$ and $2.61 \pm 2.24$ for FIB- 4 , respectively (Table S1). The optimal values of APRI, APRI 12M, FIB-4, and FIB-4 12M to differentiate HCC risk were 0.90, 0.53, 2.53, and 2.56, respectively. The sensitivity, specificity, positive predictive value (PPV), negative predictive value (NPV), and accuracy according to the optimal cutoff values of APRI and FIB-4 indices at baseline or after 1 year of treatment in predicting HCC risk are shown in Supplementary Table S2, and their areas under the receiver operating characteristic (AUROCs) curve were compared (Tables S3 and S4). The median APRI 12M, FIB-4, and FIB-4 12M values and the proportions of patients with APRI $\geq 0.90$, APRI $12 \mathrm{M} \geq 0.53, \triangle \mathrm{APRI} \geq 0$, FIB- $4 \geq 2.53$, FIB- $412 \mathrm{M} \geq 2.56$, and $\triangle \mathrm{FIB}-4 \geq 0$ were significantly different between the patients with HCC and those without HCC (Table 1).

\subsection{Baseline and On-Treatment Factors Associated with HCC Occurrence}

In all of the patients, age, cirrhosis status, DM, albumin, AST, ALT, platelets, AFP 12M, APRI $\geq 0.90$, APRI $12 \mathrm{M} \geq 0.53, \triangle \mathrm{APRI} \geq 0$, FIB- $4 \geq 2.53$, FIB-4 $12 \mathrm{M} \geq 2.56$, and $\triangle$ FIB- $4 \geq 0$ showed significant associations with HCC according to univariate Cox regression analysis (Table 2). By employing multivariate Cox regression analysis (FIB-4 based model without the inclusion of the cirrhosis factor), DM, AFP $12 \mathrm{M}$, FIB-4 12M $\geq 2.56$, and $\triangle$ FIB- $4 \geq 0$ were determined to be independent predictors of 
HCC (Table 3 and Table S5). In the noncirrhotic subgroup, FIB-4 12M $\geq 1.58$ and $\triangle$ FIB- $4 \geq 0$ were independent predictors of HCC, whereas in the cirrhotic subgroup, sex, DM, AFP 12M, FIB-4 12M $\geq 2.88$, and $\triangle$ FIB- $4 \geq 0$ were independent predictors of HCC. These results were obtained through multivariate Cox regression analysis (Table 3). The results of univariate Cox regression analysis are shown in Tables S6 and S7.

Table 1. Baseline and on-treatment characteristics of treatment-naïve patients with chronic hepatitis B (CHB) $(n=1325)$.

\begin{tabular}{|c|c|c|c|c|}
\hline \multirow{2}{*}{$\begin{array}{c}\text { Variables } \\
\text { Median } \pm \text { IQR or } n(\%)\end{array}$} & \multirow{2}{*}{$\begin{array}{c}\text { Total } \\
n=1325\end{array}$} & \multicolumn{2}{|c|}{ HCC Occurrence } & \multirow{2}{*}{$p$ Value } \\
\hline & & Yes $(n=105)$ & No $(n=1220)$ & \\
\hline Age (years) & $50 \pm 17$ & $58 \pm 14$ & $49 \pm 17$ & $<0.0001$ \\
\hline Sex (male) & $963(72.7)$ & $79(75.2)$ & $884(72.5)$ & 0.5397 \\
\hline HBeAg-positive status & $475(35.8)$ & $29(27.6)$ & $446(36.6)$ & 0.0669 \\
\hline Cirrhosis status & $481(36.3)$ & $93(88.6)$ & $388(31.8)$ & $<0.0001$ \\
\hline Diabetes mellitus (yes) & 158 (11.9) & $22(21.0)$ & $136(11.1)$ & 0.0029 \\
\hline Albumin, $\mathrm{g} / \mathrm{dL}$ & $4.11 \pm 0.6$ & $3.9 \pm 0.7$ & $4.2 \pm 0.6$ & $<0.0001$ \\
\hline AST, U/L & $72 \pm 115$ & $60 \pm 46$ & $73 \pm 123$ & 0.0028 \\
\hline ALT, U/L & $106 \pm 207$ & $64 \pm 59$ & $113 \pm 220$ & $<0.0001$ \\
\hline Total bilirubin, $\mathrm{mg} / \mathrm{dL}$ & $1 \pm 0.78$ & $1.1 \pm 0.7$ & $1 \pm 0.8$ & 0.5459 \\
\hline INR & $1.08 \pm 0.15$ & $1.11 \pm 0.17$ & $1.07 \pm 0.14$ & 0.0090 \\
\hline Platelets, $\times 10^{3} / \mu \mathrm{L}$ & $163 \pm 76$ & $120 \pm 70$ & $167 \pm 73.5$ & $<0.0001$ \\
\hline \multicolumn{5}{|l|}{ Histology grading } \\
\hline F $1 / 2 / 3 / 4 / \mathrm{NA}$ & $57 / 84 / 30 / 122 / 1032$ & 0/2/1/17/85 & $57 / 82 / 29 / 105 / 947$ & \\
\hline A $0 / 1 / 2 / 3 / N A$ & $40 / 138 / 64 / 51 / 1032$ & $3 / 11 / 2 / 4 / 85$ & $37 / 127 / 62 / 47 / 947$ & \\
\hline $\mathrm{AFP}, \mathrm{ng} / \mathrm{mL}$ & $6.01 \pm 10.31$ & $8.25 \pm 11.94$ & $5.82 \pm 10.18$ & 0.0002 \\
\hline AFP $12 \mathrm{M}, \mathrm{ng} / \mathrm{mL}$ & $3.41 \pm 2.35$ & $5.63 \pm 4.63$ & $3.28 \pm 2.09$ & $<0.0001$ \\
\hline HBV DNA, $\log \mathrm{IU} / \mathrm{mL}$ & $5.96 \pm 7.28$ & $5.49 \pm 6.46$ & $6.04 \pm 7.34$ & $<0.0001$ \\
\hline Time to VR (M) & $6.0(6.3)$ & $6.0(0)$ & $6.0(6.4)$ & 0.9267 \\
\hline VR $12 M$ (yes) & $1160(87.5)$ & $98(93.3)$ & $1062(87)$ & 0.0613 \\
\hline APRI & $1.22 \pm 2.1$ & $1.43 \pm 1.73$ & $1.19 \pm 2.13$ & 0.1881 \\
\hline APRI $(\geq 0.90)$ & $855(64.5)$ & $80(76.2)$ & 775 (63.5) & 0.0092 \\
\hline APRI 12M & $0.42 \pm 0.37$ & $1.04 \pm 0.67$ & $0.41 \pm 0.31$ & $<0.0001$ \\
\hline APRI 12M ( $\geq 0.53)$ & $473(35.7)$ & $92(87.6)$ & 381 (31.2) & $<0.0001$ \\
\hline$\triangle \mathrm{APRI}(12 \mathrm{M}-0 \mathrm{M})(\geq 0)$ & $136(10.3)$ & $33(31.4)$ & $103(8.4)$ & $<0.0001$ \\
\hline FIB-4 & $2.45 \pm 2.69$ & $4.09 \pm 4.03$ & $2.37 \pm 2.51$ & $<0.0001$ \\
\hline FIB-4 ( $\geq 2.53)$ & $637(48.1)$ & $82(78.1)$ & $555(45.5)$ & $<0.0001$ \\
\hline FIB-4 12M & $1.64 \pm 1.56$ & $4.09 \pm 3.22$ & $1.55 \pm 1.38$ & $<0.0001$ \\
\hline FIB-4 12M ( $\geq 2.56)$ & $342(25.8)$ & $84(80.0)$ & $258(21.1)$ & $<0.0001$ \\
\hline$\triangle$ FIB-4 $(12 \mathrm{M}-0 \mathrm{M})(\geq 0)$ & $323(24.4)$ & $60(57.1)$ & $263(21.6)$ & $<0.0001$ \\
\hline Treatment duration (year) & $4.09(2.94)$ & $3.29(2.32)$ & $4.11(3.00)$ & $<0.0001$ \\
\hline Follow-up period (year) & $4.09(2.94)$ & $3.29(2.32)$ & $4.11(3.00)$ & $<0.0001$ \\
\hline
\end{tabular}

Abbreviations: AFP-alpha-fetoprotein; ALT-alanine aminotransferase; AST-aspartate aminotransferase APRI-AST/PLT ratio index; CHB — chronic hepatitis B; DNA—deoxyribonucleic acid; FIB-4-fibrosis index based on four factors; HBeAg-hepatitis B e antigen; HBV—hepatitis B virus; HCC - hepatocellular carcinoma; INR—international normalised ratio; IQR - interquartile range; $\mathrm{M}$ - month; NA—not available; PLT—platelet; VR-virological response.

\subsection{Cumulative Incidence of HCC Stratified by 1-Year FIB-4 Values or On-Treatment Changes in FIB-4}

The results of our multivariate Cox regression analysis revealed that FIB-4 $12 \mathrm{M}$ and $\triangle$ FIB-4 were independent predictors for HCC in all of the patients and subgroups with and without cirrhosis. In Figure 1, both FIB-4 12M and $\triangle$ FIB-4 are shown to stratify the risk of HCC (log-rank test of both $p<0.0001$ ). The 5 -year cumulative incidences of HCC stratified by FIB- $412 \mathrm{M}$ were $27.2 \%$ vs. $2.7 \%$ for all of the patients with FIB- $412 \mathrm{M} \geq 2.56$ vs. $<2.56 ; 5.9 \%$ vs. $0.2 \%$ for noncirrhotic patients with FIB- $412 \mathrm{M} \geq 1.58$ vs. $<1.58$; and $33.5 \%$ vs. $8 \%$ for the cirrhotic patients with FIB- $412 \mathrm{M} \geq 2.88$ vs. $<2.88$. 
Table 2. Univariate Cox regression analysis of risk factors associated with HCC $(n=105)$ in all patients $(n=1325)$.

\begin{tabular}{|c|c|c|}
\hline \multirow{2}{*}{$\begin{array}{c}\text { Variables } \\
\text { Median } \pm \text { IQR or } n(\%)\end{array}$} & \multicolumn{2}{|c|}{ Univariate } \\
\hline & Hazard Ratio (95\% CI) & $p$ Value \\
\hline Age (year) & $1.056(1.039-1.074)$ & $<0.0001$ \\
\hline Sex, male vs. female & $1.103(0.708-1.718)$ & 0.6653 \\
\hline HBeAg, positive vs. negative & $0.717(0.467-1.100)$ & 0.1272 \\
\hline Cirrhosis status, yes vs. no & $11.29(6.180-20.63)$ & $<0.0001$ \\
\hline Diabetes mellitus, yes vs. no & $2.280(1.424-3.650)$ & 0.0006 \\
\hline Albumin, $\mathrm{g} / \mathrm{dL}$ & $0.406(0.294-0.559)$ & $<0.0001$ \\
\hline AST, U/L & $0.998(0.997-1.000)$ & 0.0117 \\
\hline ALT, U/L & $0.998(0.996-0.999)$ & 0.0006 \\
\hline Total bilirubin, $\mathrm{mg} / \mathrm{dL}$ & $0.929(0.829-1.042)$ & 0.2087 \\
\hline INR & $1.618(0.866-3.021)$ & 0.1311 \\
\hline Platelets, $\times 10^{3} / \mu \mathrm{L}$ & $0.985(0.982-0.989)$ & $<0.0001$ \\
\hline $\mathrm{AFP}, \mathrm{ng} / \mathrm{mL}$ & $0.999(0.996-1.001)$ & 0.3951 \\
\hline AFP $12 \mathrm{M}, \mathrm{ng} / \mathrm{mL}$ & 1.005 (1.002-1.007) & $<0.0001$ \\
\hline HBV DNA, $\log I U / m L$ & $1.000(1.000-1.000)$ & 0.1854 \\
\hline VR 12M, yes vs. no & $1.931(0.897-4.159)$ & 0.0925 \\
\hline APRI, $\geq 0.90$ vs. $<0.90$ & $1.991(1.270-3.121)$ & 0.0027 \\
\hline APRI $12 \mathrm{M}, \geq 0.53$ vs. $<0.53$ & 11.79 (6.596-21.09) & $<0.0001$ \\
\hline$\triangle \mathrm{APRI}(12 \mathrm{M}-0 \mathrm{M}), \geq 0$ vs. $<0$ & $3.845(2.546-5.807)$ & $<0.0001$ \\
\hline FIB- $4, \geq 2.53$ vs. $<2.53$ & $3.919(2.467-6.223)$ & $<0.0001$ \\
\hline FIB- $412 \mathrm{M}, \geq 2.56$ vs. $<2.56$ & 11.31 (7.009-18.25) & $<0.0001$ \\
\hline$\triangle$ FIB-4 $(12 \mathrm{M}-0 \mathrm{M}), \geq 0$ vs. $<0$ & $3.953(2.685-5.819)$ & $<0.0001$ \\
\hline
\end{tabular}

Abbreviations: AFP-alpha-fetoprotein; ALT-alanine aminotransferase; AST-aspartate aminotransferase; APRI—AST/PLT ratio index; $\mathrm{CHB}$-chronic hepatitis B; CI—confidence interval; DNA—deoxyribonucleic acid; FIB-4-fibrosis index based on four factors; HBeAg-hepatitis B e antigen; HBV-hepatitis B virus; $\mathrm{HCC}-$ hepatocellular carcinoma; INR - international normalised ratio; IQR—interquartile range; $\mathrm{M}-$ month; PLT—platelet; VR-virological response.

Table 3. Multivariate Cox regression analysis of risk factors (FIB- 4 based model) associated with HCC in patients with noncirrhotic and cirrhotic CHB.

\begin{tabular}{ccc}
\hline Risk Factors & \multicolumn{2}{c}{ Multivariate } \\
\cline { 2 - 3 } & Hazard Ratio (95\% CI) & $p$ Value \\
\hline All patients $(n=$ 1325) & $1.726(1.076-2.770)$ & 0.0235 \\
\hline Diabetes mellitus, yes vs. no & $1.005(1.003-1.008)$ & $<0.0001$ \\
AFP 12M, ng/mL & $9.198(5.610-15.08)$ & $<0.0001$ \\
FIB-4 12M, $\geq 2.56$ vs. $<2.56$ & $2.353(1.585-3.495)$ & $<0.0001$ \\
$\Delta$ FIB-4 (12M-0M), $\geq 0$ vs. $<0$ & & \\
\hline Noncirrhotic patients $(n=844)$ & $12.10(1.531-95.60)$ & 0.0181 \\
\hline FIB-4 12M, $\geq 1.58$ vs. $<1.58$ & $7.013(1.874-26.24)$ & 0.0038 \\
$\triangle$ FIB-4 (12M-0M), $\geq 0$ vs. $<0$ & & \\
\hline Cirrhotic patients $(n=481)$ & $1.758(1.082-2.856)$ & 0.0226 \\
\hline Sex, male vs. female & $1.665(1.006-2.756)$ & 0.0472 \\
Diabetes mellitus, yes & $1.008(1.005-1.012)$ & $<0.0001$ \\
AFP 12M, ng/mL & $4.821(2.908-7.992)$ & $<0.0001$ \\
FIB-4 12M, $\geq 2.88$ vs. $<2.88$ & $1.981(1.301-3.016)$ & 0.0014 \\
$\triangle$ FIB-4 (12M-0M), $\geq 0$ vs. $<0$ &
\end{tabular}

Abbreviations: AFP—alpha-fetoprotein; CHB-chronic hepatitis B; CI—confidence interval; FIB-4—fibrosis index based on four factors; $\mathrm{HCC}$-hepatocellular carcinoma; $\mathrm{M}-$ month. 

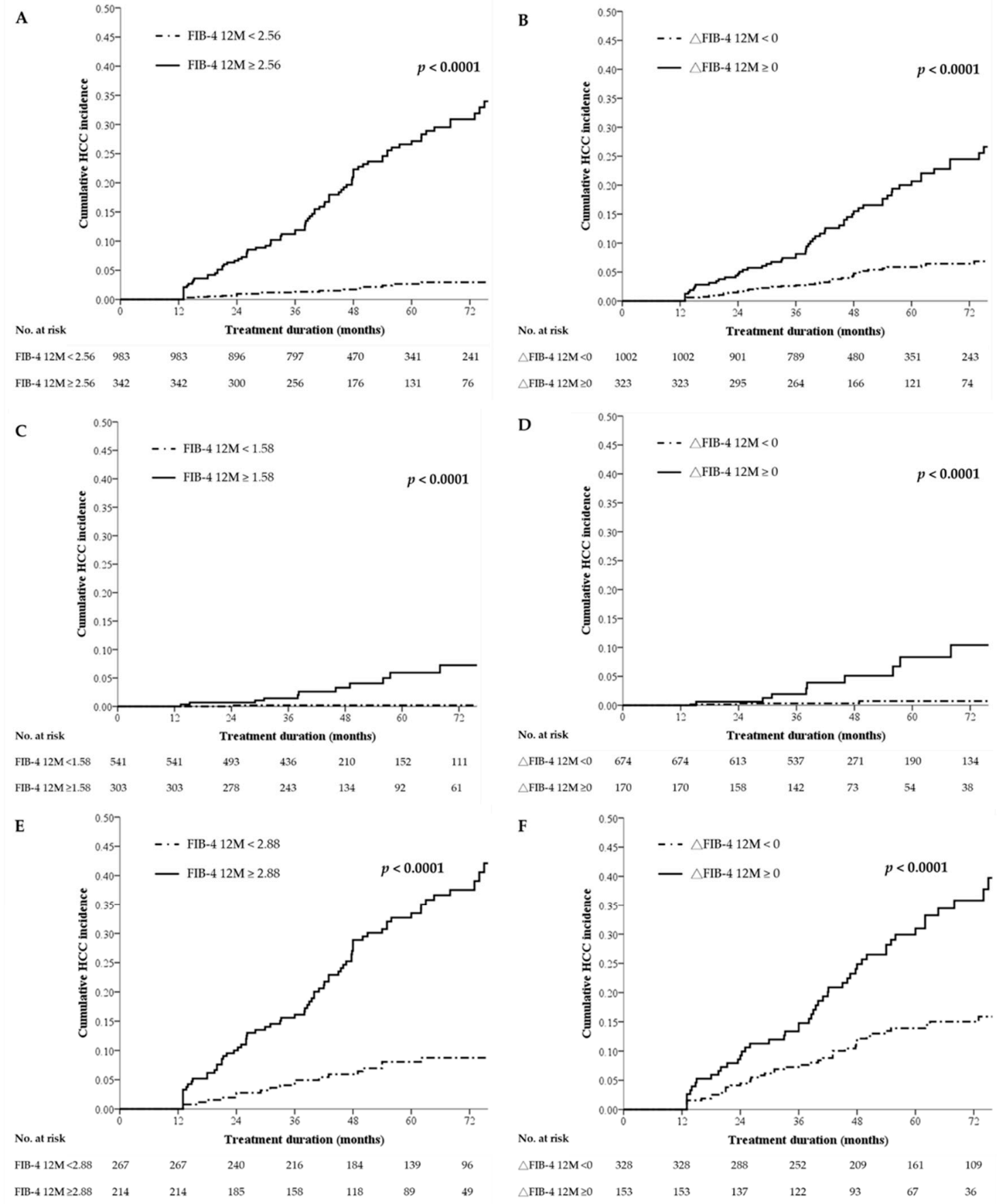

Figure 1. HCC risk stratification by FIB-4 $12 \mathrm{M}$ or $\triangle$ FIB-4 in treatment-naive patients with CHB: all patients (A,B), noncirrhotic patients $(\mathbf{C}, \mathbf{D})$, and cirrhotic patients $(\mathbf{E}, \mathbf{F})$. CHB-chronic hepatitis B; FIB-4-fibrosis index based on four factors; HCC - hepatocellular carcinoma; $\mathrm{M}$ - months.

\subsection{Comparison of Baseline Characteristics among the Subgroups Stratified by On-Treatment Changes in FIB-4}

According to the on-treatment changes in FIB-4, we categorised the treatment-naïve patients with CHB into subgroups with $\triangle$ FIB- $4<0(n=1002)$ or $\triangle$ FIB- $4 \geq 0(n=323)$ (Table 4$)$. Older age (51 \pm 16 years); a higher percentage of cirrhosis and HCC; lower AST, ALT, total bilirubin, INR, AFP, HBV DNA, FIB-4, and platelets 12M; and higher AST 12M, ALT 12M, AFP 12M, and FIB-4 12M were significantly associated with the subgroup with $\triangle$ FIB- $4 \geq 0$ (Table 4). Further analyses of the noncirrhotic and cirrhotic patients revealed that lower AST, ALT, total bilirubin, INR, AFP, HBV DNA, FIB-4, and platelets 12M; and higher platelets, AST 12M, ALT 12M, and FIB-4 12M were significantly 
associated with the subgroup with $\triangle$ FIB-4 $\geq 0$ (Tables S8 and S9). In all $(n=105)$ or cirrhotic patients ( $n=93$ ) with HCC, lower AST, ALT, total bilirubin, AFP, FIB-4, and platelets 12M; and higher AST 12M and FIB-4 12M were significantly associated with the subgroup with $\triangle$ FIB-4 $\geq 0$ (Tables S10 and S11). In noncirrhotic patients with HCC $(n=12)$, only lower AFP $12 \mathrm{M}$ was significantly associated with the subgroup with $\triangle$ FIB- $4 \geq 0$, perhaps because of small number of cases (Table S12).

Table 4. Characteristics of treatment-naïve patients with $\mathrm{CHB}$ stratified by $\triangle \mathrm{FIB}-4$.

\begin{tabular}{|c|c|c|c|}
\hline $\begin{array}{c}\text { Variables } \\
\text { Median } \pm \text { IQR or } n(\%)\end{array}$ & $\begin{array}{c}\triangle \text { FIB-4 }<0 \\
n=1002\end{array}$ & $\begin{array}{c}\triangle \text { FIB- } 4 \geq 0 \\
n=323\end{array}$ & $p$ Value \\
\hline \multicolumn{4}{|l|}{ Baseline } \\
\hline Age (years) & $49 \pm 17$ & $51 \pm 16$ & 0.002 \\
\hline Sex (male) & 727 (72.6) & $236(73.1)$ & 0.719 \\
\hline $\begin{array}{l}\text { HBeAg-positive status } \\
\text { (yes) }\end{array}$ & $367(36.6)$ & $108(33.4)$ & 0.298 \\
\hline Diabetes mellitus (yes) & $120(11.9)$ & $38(11.8)$ & 0.919 \\
\hline Cirrhosis (yes) & $328(32.7)$ & $153(47.4)$ & $<0.001$ \\
\hline $\mathrm{HCC}$ & $45(4.5)$ & $60(18.6)$ & $<0.001$ \\
\hline Albumin, $\mathrm{g} / \mathrm{dL}$ & $4.1 \pm 0.6$ & $4.2 \pm 0.5$ & 0.163 \\
\hline AST, U/L & $92 \pm 187$ & $46 \pm 26$ & $<0.001$ \\
\hline ALT, U/L & $137 \pm 316$ & $60 \pm 50$ & $<0.001$ \\
\hline Total bilirubin, $\mathrm{mg} / \mathrm{dL}$ & $1.1 \pm 1.0$ & $0.9 \pm 0.6$ & $<0.001$ \\
\hline INR & $1.09 \pm 0.16$ & $1.06 \pm 0.13$ & $<0.001$ \\
\hline Platelets, $\times 10^{3} / \mu \mathrm{L}$ & $162 \pm 75$ & $166 \pm 83$ & 0.297 \\
\hline $\mathrm{AFP}, \mathrm{ng} / \mathrm{mL}$ & $6.53 \pm 13.3$ & $4.87 \pm 5.25$ & $<0.001$ \\
\hline HBV DNA, $\log I U / m L$ & $6.19 \pm 7.43$ & $5.36 \pm 6.54$ & $<0.001$ \\
\hline FIB-4 & $2.69 \pm 3.00$ & $1.73 \pm 1.72$ & $<0.001$ \\
\hline \multicolumn{4}{|l|}{ One-year treatment } \\
\hline AST 12M, U/L & $26 \pm 11$ & $31 \pm 16$ & $<0.001$ \\
\hline ALT 12M, U/L & $26 \pm 16$ & $29 \pm 18$ & $<0.001$ \\
\hline Platelets $12 \mathrm{M}, \times 10^{3} / \mu \mathrm{L}$ & $171 \pm 77$ & $141 \pm 81$ & $<0.001$ \\
\hline AFP $12 \mathrm{M}, \mathrm{ng} / \mathrm{mL}$ & $3.33 \pm 2.25$ & $3.69 \pm 2.97$ & 0.009 \\
\hline VR 12M (yes) & $871(86.9)$ & $289(89.5)$ & 0.228 \\
\hline FIB-4 12M & $1.53 \pm 1.36$ & $2.11 \pm 2.34$ & $<0.001$ \\
\hline
\end{tabular}

Abbreviations: AFP—alpha-fetoprotein; ALT—alanine aminotransferase; AST-aspartate aminotransferase; CHB-chronic hepatitis B; DNA-deoxyribonucleic acid; FIB-4-fibrosis index based on four factors; HBV-hepatitis B virus; HCC-hepatocellular carcinoma; INR-international normalised ratio; $\mathrm{IQR}$-interquartile range; $\mathrm{M}$-months; VR—virological response.

\subsection{Cumulative Incidence of HCC Stratified by the Combination of On-Treatment Changes in FIB-4 and 1-Year} FIB-4 Values

For the entire cohort, a combination of FIB-4 $12 \mathrm{M}$ and $\triangle$ FIB- 4 could stratify the cumulative risk of HCC into four subgroups ( $p<0.0001$ by the log-rank test). Among them, 135 with FIB-4 12M $\geq 2.56$ and $\triangle$ FIB-4 $\geq 0$ exhibited the highest risk of HCC (HR: 25.58, 95\% CI: 13.31-49.15, $p<0.0001$ ), and 795 with FIB-4 $12 \mathrm{M}<2.56$ and $\triangle$ FIB- $4<0$ exhibited the lowest risk of HCC (HR: 1 as reference) (Table 5, Figure $2 \mathrm{~A}$. A combination of FIB-4 $12 \mathrm{M}$ and $\triangle \mathrm{FIB}-4$ was used to stratify the cumulative risk of HCC into three subgroups in the noncirrhotic and cirrhotic subgroups (each subgroup $p<0.0001$ by the log-rank test). Among the noncirrhotic patients, 88 with FIB-4 $12 \mathrm{M} \geq 1.58$ and $\triangle$ FIB- $4 \geq 0$ exhibited the highest risk of HCC (HR: 40.35, 95\% CI: 5.107-318.7, $p<0.0001$ ), and 459 with FIB-4 $12 \mathrm{M}<1.58$ and $\triangle$ FIB-4 $<0$ exhibited the lowest risk of HCC (HR: 1 as reference) (Table 5, Figure 2B). Among the cirrhotic patients, 89 with FIB-4 $12 \mathrm{M} \geq 2.88$ and $\triangle$ FIB- $4 \geq 0$ exhibited the highest risk of HCC (HR: 9.576, 95\% CI: 5.033-18.22, $p<0.0001$ ), and 203 with FIB-4 $12 \mathrm{M}<2.88$ and $\triangle$ FIB- $4<0$ exhibited the lowest risk of HCC (HR: 1 as reference) (Table 5, Figure 2C). 
Table 5. HCC risk stratification by a combination of FIB-4 $12 \mathrm{M}$ and $\triangle \mathrm{FIB}-4$ in patients with $\mathrm{CHB}$.

\begin{tabular}{|c|c|c|c|}
\hline Combined risk factors & Crude HR & $95 \% \mathrm{CI}$ & $p$ Value \\
\hline \multicolumn{4}{|l|}{ All patients $(n=1325)$} \\
\hline $\begin{array}{c}\text { FIB-4 } 12 \mathrm{M}<2.56 \text { and } \triangle \text { FIB- } 4<0 \\
(n=795)\end{array}$ & 1 & & \\
\hline $\begin{array}{c}\text { FIB-4 } 12 \mathrm{M}<2.56 \text { and } \triangle \text { FIB- } 4 \geq 0 \\
(n=188)\end{array}$ & 3.673 & $1.560-8.649$ & 0.0029 \\
\hline $\begin{array}{c}\text { FIB-4 } 12 \mathrm{M} \geq 2.56 \text { and } \triangle \text { FIB- } 4<0 \\
(n=207)\end{array}$ & 11.74 & $5.948-23.18$ & $<0.0001$ \\
\hline $\begin{array}{l}\text { FIB-4 } 12 \mathrm{M} \geq 2.56 \text { and } \triangle \text { FIB- } 4 \geq 0 \\
\qquad(n=135)\end{array}$ & 25.58 & $13.31-49.15$ & $<0.0001$ \\
\hline \multicolumn{4}{|l|}{ Noncirrhotic patients $(n=844)$} \\
\hline $\begin{array}{c}\text { FIB-4 } 12 \mathrm{M}<1.58 \text { and } \triangle \text { FIB }-4<0 \\
(n=459)\end{array}$ & 1 & & \\
\hline \multicolumn{4}{|l|}{ FIB- $412 \mathrm{M} \geq 1.58$ and $\triangle$ FIB $-4<0$ or } \\
\hline $\begin{array}{c}\text { FIB-4 } 12 \mathrm{M}<1.58 \text { and } \triangle \text { FIB- } 4 \geq 0 \\
(n=297)\end{array}$ & 3.076 & $0.279-33.93$ & 0.3589 \\
\hline $\begin{array}{c}\text { FIB-4 } 12 \mathrm{M} \geq 1.58 \text { and } \triangle \text { FIB- } 4 \geq 0 \\
(n=88)\end{array}$ & 40.35 & $5.107-318.7$ & $<0.0001$ \\
\hline \multicolumn{4}{|l|}{ Cirrhotic patients $(n=481)$} \\
\hline $\begin{array}{c}\text { FIB-4 } 12 \mathrm{M}<2.88 \text { and } \triangle \text { FIB- } 4<0 \\
\quad(n=203)\end{array}$ & 1 & & \\
\hline \multicolumn{4}{|l|}{ FIB- $412 \mathrm{M} \geq 2.88$ and $\triangle$ FIB- $4<0$ or } \\
\hline $\begin{array}{c}\text { FIB-4 } 12 \mathrm{M}<2.88 \text { and } \triangle \text { FIB- } 4 \geq 0 \\
(n=189)\end{array}$ & 3.625 & $1.897-6.927$ & $<0.0001$ \\
\hline $\begin{array}{c}\text { FIB-4 } 12 \mathrm{M} \geq 2.88 \text { and } \triangle \text { FIB- } 4 \geq 0 \\
(n=89)\end{array}$ & 9.576 & $5.033-18.22$ & $<0.0001$ \\
\hline
\end{tabular}

Abbreviations: $\mathrm{CHB}$ - chronic hepatitis B; CI—confidence interval; FIB-4—fibrosis index based on four factors; HCC—hepatocellular carcinoma; HR—hazard ratio; $\mathrm{M}$ - months.
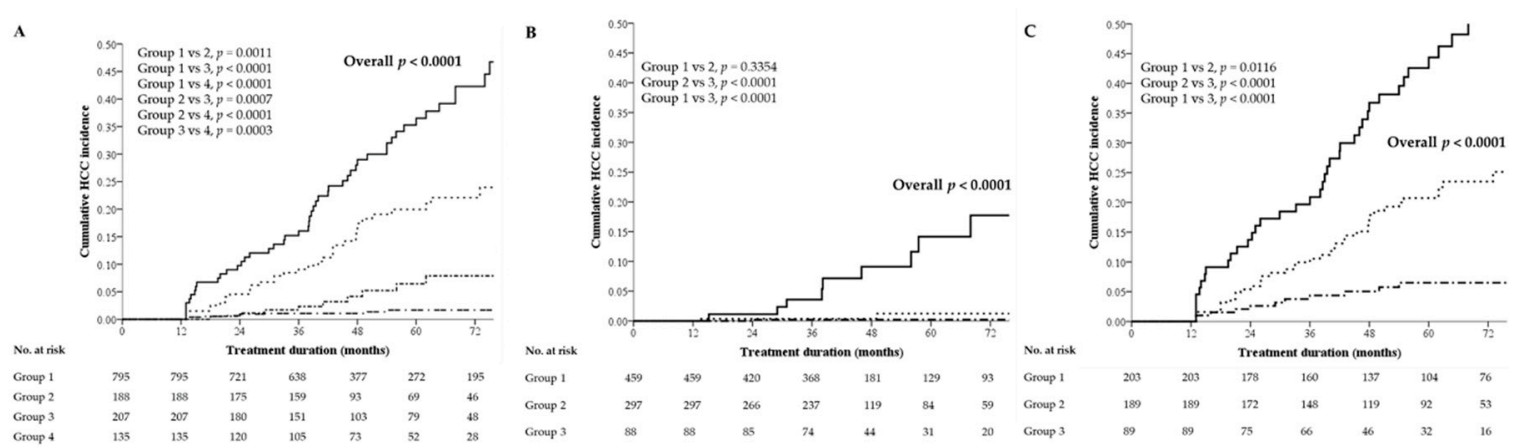

Figure 2. HCC risk stratification by a combination of FIB-4 $12 \mathrm{M}$ and $\triangle$ FIB-4. (A) All patients: - - Group 1, FIB-4 12M $<2.56$ and $\triangle$ FIB-4 $<0 ; \cdots \cdot$ Group 2, FIB-4 $12 \mathrm{M}<2.56$ and $\triangle$ FIB-4 $\geq 0$; ... Group 3, FIB-4 12M $\geq 2.56$ and $\triangle$ FIB-4 $<0$; — Group 4, FIB-4 $12 \mathrm{M} \geq 2.56$ and $\triangle$ FIB-4 $\geq 0$. (B) Noncirrhotic patients: - - Group 1, FIB-4 $12 \mathrm{M}<1.58$ and $\triangle$ FIB-4 $<0$; $\cdots$ Group 2, FIB-4 $12 \mathrm{M} \geq 1.58$ and $\triangle$ FIB-4 $<0$ or FIB-4 $12 \mathrm{M}<1.58$ and $\triangle$ FIB-4 $\geq 0 ;-$ Group 3, FIB-4 $12 \mathrm{M} \geq 1.58$ and $\triangle$ FIB-4 $\geq 0$. (C) Cirrhotic patients: $-\cdots$ - Group 1, FIB-4 $12 \mathrm{M}<2.88$ and $\triangle$ FIB- $4<0 ; \cdots$ Group 2 FIB- $412 \mathrm{M} \geq 2.88$ and $\triangle$ FIB- $4<0$ or FIB- $412 \mathrm{M}<2.88$ and $\triangle$ FIB- $4 \geq 0$; - Group 3 FIB- $412 \mathrm{M} \geq 2.88$ and $\triangle$ FIB-4 $\geq 0$. FIB-4-fibrosis index based on four factors; HCC-hepatocellular carcinoma; $\mathrm{M}-$ months.

We summarise the predictive algorithm for HCC risk in the patients with CHB treated with entecavir according to FIB-4 12M (optimal cutoff value of 2.56 for the entire cohort) and $\triangle$ FIB-4 (Figure $3 \mathrm{~A}$ ) or their baseline liver cirrhosis status, FIB-4 12M (optimal cutoff values of 1.58 for the noncirrhotic subgroup and 2.88 for the cirrhotic subgroup), and $\triangle \mathrm{FIB}-4$ (Figure $3 \mathrm{~B}$ ). Regardless of baseline liver cirrhosis status, CHB patients who achieved FIB-4 $12 \mathrm{M}<2.56 / \triangle \mathrm{FIB}-4<0$ exhibited cumulative 3- and 5-year HCC risks of $1.1 \%$ and $1.7 \%$, respectively, and those who 
achieved FIB-4 $12 \mathrm{M} \geq 2.56 / \triangle \mathrm{FIB}-4 \geq 0$ exhibited the highest 3- and 5-year HCC risks of $15.2 \%$ and $35.3 \%$, respectively (Figure 3A). The noncirrhotic patients who achieved FIB-4 $12 \mathrm{M}<1.58$ or FIB- $412 \mathrm{M} \geq 1.58 / \triangle$ FIB- $4<0$ exhibited cumulative 3 - and 5-year HCC risks of $0.3 \%$ and $0.6 \%$, respectively. The cirrhotic patients who achieved FIB-4 $12 \mathrm{M} \geq 2.88 / \triangle \mathrm{FIB}-4 \geq 0$ exhibited the highest 3- and 5-year HCC risks of $20.9 \%$ and $44.4 \%$, respectively (Figure $3 \mathrm{~B}$ ).

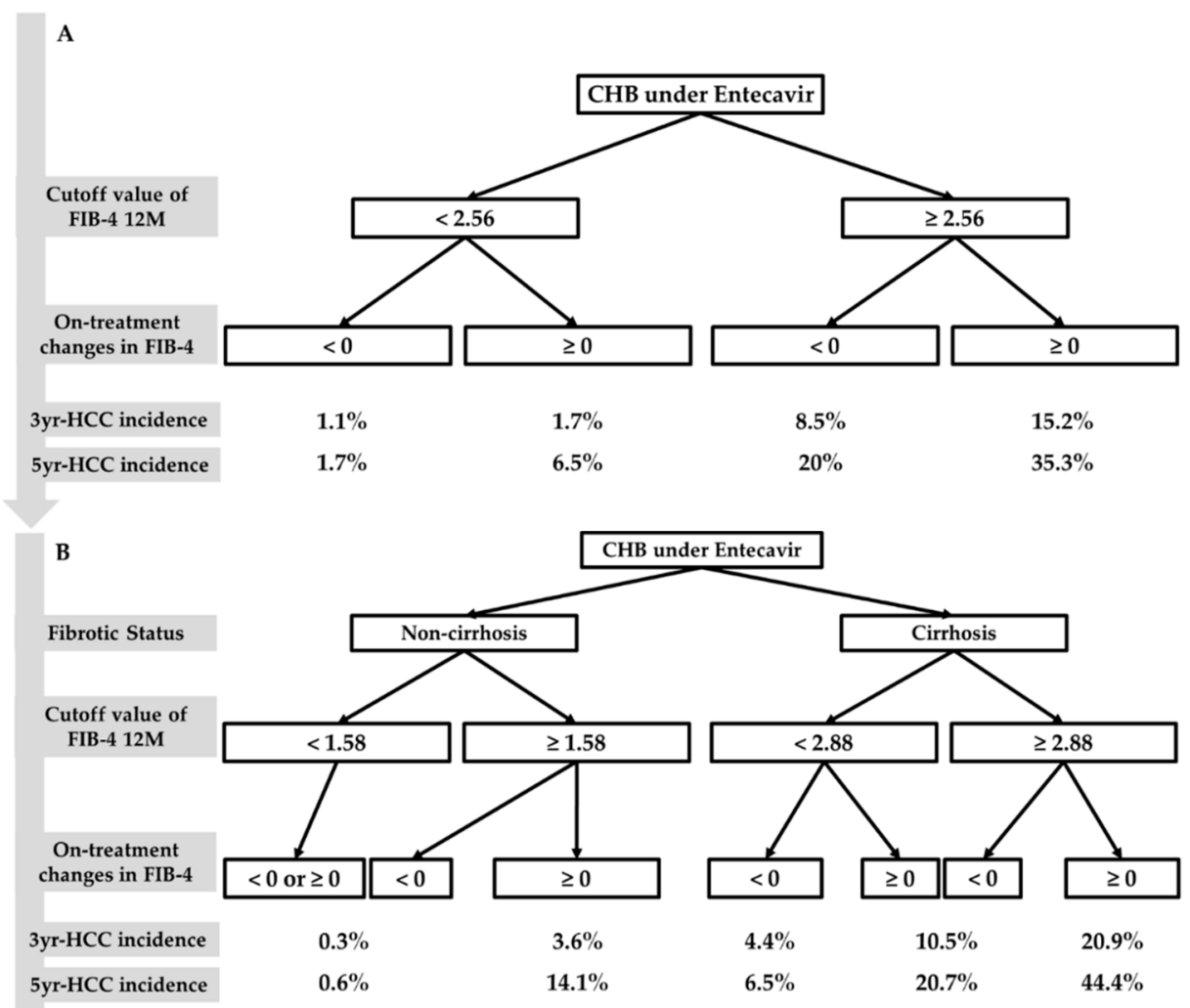

Figure 3. Algorithm for the prediction of HCC risk in $\mathrm{CHB}$ patients (A) without stratification by baseline liver fibrosis status and (B) stratified by baseline liver fibrosis status. $\mathrm{CHB}$-chronic hepatitis B; FIB-4-fibrosis index based on four factors; HCC — hepatocellular carcinoma; M-months; yr-years.

\subsection{Performance of the Predictive Algorithm for HCC in the Cirrhotic Subgroup with Liver Biopsies}

Because liver cirrhosis was only verified by histology in 122 patients, we attempted to derive the optimal cutoffs for APRI, APRI 12M, FIB-4, and FIB-4 12M and determine their AUROCs, sensitivity, specificity, PPV, NPV, and accuracy in predicting HCC risk (Tables S13 and S14). Although they were significantly associated with HCC according to univariate Cox regression analysis, they could not coexist in the same multivariate Cox regression model (Table S15). Therefore, we validated the performance of the predictive algorithm in this subgroup of patients. The AUROCs of the various FIB-4-based and APRI-based algorithms for predicting HCC risk in all cirrhotic patients and the cirrhotic subgroup with liver biopsies were comparable (Table S13). The AUROCs of APRI 12M and FIB-4 12M for predicting HCC risk in the subgroup with liver biopsies were numerically higher than those in all cirrhotic patients (Table S13). The AUROCs of FIB-4 12M for predicting HCC risk were numerally higher than those of APRI 12M and significantly higher than those of FIB-4 and APRI in all cirrhotic patients and the subgroup with liver biopsies (Table S14). Similarly, a combination of FIB-4 $12 \mathrm{M}$ and $\triangle$ FIB- 4 could stratify the cumulative risk of HCC into three subgroups in the cirrhotic subgroup with liver biopsies ( $p<0.001$ by the log-rank test) (Figure $\mathrm{S} 1$ ). 


\subsection{Performance of the Predictive Algorithm in Cohorts Who Received 3 or 5 Years of Continuous Entecavir Therapy}

To further validate the performance of the predictive algorithm in patients who had received entecavir therapy for a longer period, we selected the cohorts of patients who had received $\geq 3(n=1053)$ and $\geq 5$ years $(n=472)$ of continuous entecavir therapy for further analysis. The AUROCs of the various FIB-4-based and APRI-based algorithms for predicting HCC risk in all patients, the 3-year cohort, or the 5-year cohort, in either the noncirrhotic or cirrhotic subgroup, were comparable (Table S16). The sensitivity, specificity, PPV, NPV, and accuracy according to the cutoff values for APRI and FIB-4 indices at baseline or after 1 year of treatment in predicting HCC risk in these two cohorts are shown in Tables S17 and S18.

In the patients who received $\geq 3$ years of continuous entecavir therapy, a combination of FIB- $412 \mathrm{M}$ and $\triangle$ FIB-4 could stratify the cumulative risk of HCC into four subgroups in all patients $(p<0.0001$ by the log-rank test), or into three subgroups in the noncirrhotic or cirrhotic subgroup (each subgroup $p<0.0001$ by the log-rank test) (Figure S2). These results are in line with those for the entire cohort (Figure 2).

\subsection{Comparison of AUROCs among Different HCC Prediction Models}

Until now, some simple HCC risk prediction models for treatment-naïve CHB patients or patients under long-term NA therapy have been proposed, such as PAGE-B, REACH-B, CU-HCC, APA-B, CAGE-B, and SAGE-B scores [19-26]. We determined the C-statistic and time-dependent AUROCs of the proposed FIB-4-based predictive algorithm and the PAGE-B, REACH-B, CU-HCC, and APA-B scores, which we were able to calculate for predicting HCC risk after 2-5 years of entecavir therapy (Table 6). The APA-B score and FIB-4-based model had significantly higher predictive performance in predicting HCC risk compared to the other scores (Table 6, Table S19). The APA-B score and FIB-4-based model had similar performance except after 3 years of entecavir therapy.

Table 6. C-statistic and time-dependent AUROCs for predicting HCC risk by using different risk scores.

\begin{tabular}{cccccc}
\hline \multirow{2}{*}{ Risk Scores } & PAGE-B & REACH-B & CU-HCC & APA-B & $\begin{array}{c}\text { FIB-4-Based } \\
\text { Model }\end{array}$ \\
\cline { 2 - 6 } & AUROC & AUROC & AUROC & AUROC & AUROC \\
& $\mathbf{( 9 5 \% ~ C I ) ~}$ & $\mathbf{( 9 5 \% ~ C I ) ~}$ & $\mathbf{( 9 5 \% ~ C I ) ~}$ & $\mathbf{( 9 5 \% ~ C I ) ~}$ & $\mathbf{( 9 5 \% ~ C I ) ~}$ \\
\hline \multirow{2}{*}{ 2 years } & 0.7379 & 0.6673 & 0.7666 & 0.8815 & 0.8192 \\
& $(0.6526-0.8233)$ & $(0.5801-0.7545)$ & $(0.7033-0.8298)$ & $(0.8236-0.9395)$ & $(0.7482-0.8902)$ \\
3 years & 0.7415 & 0.6640 & 0.7771 & 0.8820 & 0.8359 \\
& $(0.6741-0.8089)$ & $(0.5950-0.7329)$ & $(0.7210-0.8333)$ & $(0.8393-0.9247)$ & $(0.7858-0.8860)$ \\
4 years & 0.7665 & 0.6679 & 0.7857 & 0.8910 & 0.8701 \\
& $(0.7163-0.8167)$ & $(0.6112-0.7246)$ & $(0.7433-0.8280)$ & $(0.8591-0.9229)$ & $(0.8341-0.9060)$ \\
5 years & 0.7471 & 0.6535 & 0.7809 & 0.8775 & 0.8659 \\
C-statistic & $(0.6980-0.7962)$ & $(0.5992-0.7078)$ & $(0.7394-0.8225)$ & $(0.8450-0.9100)$ & $(0.8321-0.8997)$ \\
& 0.7394 & 0.6551 & 0.7755 & 0.8825 & 0.8736 \\
\hline
\end{tabular}

Abbreviations: AUROC—area under the receiver operating characteristics; CI—confidence interval; FIB-4—fibrosis index based on four factors; HCC—hepatocellular carcinoma.

We further explored the ability of each model to identify patients with low-risk HCC. We calculated the cumulative incidences of HCC at 2 to 5 years of entecavir therapy among the low-risk group of patients in the present cohort according to different prediction models (Table S20). The cumulative incidences of HCC at 5 years of therapy were $2.0 \%, 0 \%, 1.9 \%$, and $2.6 \%$ among the low-risk group of patients defined by the PAGE-B, REACH-B, CU-HCC, and APA-B scores, respectively. The corresponding incidence in the low-risk noncirrhotic patients identified by the FIB-4-based model was $0.6 \%$, which compared favorably with that from the other models. Although the REACH-B model identified a subgroup of patients whose 5-year HCC risk was $0 \%$, the number of eligible patients was 
only 78, compared to 756 for the FIB-4-based model. Thus, the present predictive algorithm was able to identify a large number of patients with the lowest risk of HCC during entecavir therapy.

\section{Discussion}

A total of 105 (7.9\%) patients in the present cohort developed HCC during a median follow-up of 4.1 years with a 4 -year cumulative incidence of $7.2 \%$. The cumulative incidences of HCC after 5 years of treatment were $9.9 \%$ (noncirrhotic: $2.4 \%$ and cirrhotic: $19.3 \%$ ). A Taiwanese multicentre study in patients with predominantly compensated cirrhosis ( $90 \%$ Child-Pugh class A) reported a cumulative incidence of $11.3 \%$ after 5 years of entecavir treatment [27]. Another study in Caucasian CHB patients treated with entecavir or tenofovir for a median duration of 39 months revealed that the cumulative incidences of HCC after 5 years of treatment were $3.7 \%$ and $17.5 \%$ in the noncirrhotic and cirrhotic subgroups, respectively [28]. The incidence of HCC in untreated patients with CHB is generally believed to be higher in Asians compared to in Caucasians [29]. The factors of older age, male sex, an increased severity of liver fibrosis (e.g., a liver stiffness measurement above $12 \mathrm{kPa}$ ), a lower platelet count, and DM are associated with a higher risk of HCC in patients with CHB receiving long-term NA therapy [19-21,24-28,30]. However, the severity of liver fibrosis may be variable and subject to measurement error owing to the lack of a standardised method. This may have, in part, accounted for the varying incidences of HCC across studies [27-29]. Several risk scores have been proposed on the basis of these risk factors to predict HCC [19,21,24-26]. Obviously, liver fibrosis status is an integral component of these scores. Although current evidence suggests that elastography exhibits superior diagnostic performance to noninvasive fibrosis indices in the assessment of liver fibrosis [31], given their simplicity and availability, noninvasive fibrosis indices may be used as a surrogate marker of the severity of liver fibrosis to gauge the risk of HCC in clinical practice.

The FIB-4 index is a well-known noninvasive index that evaluates liver fibrosis in patients with CHB. Recently, the relationship between on-treatment FIB-4 values during entecavir treatment and HCC incidence has been investigated. Tada et al. reported that the FIB-4 after 24 weeks of therapy had adequate predictive performance for HCC incidence in patients with $\mathrm{CHB}$ according to a time-dependent ROC analysis [32]. An FIB-4 value $\geq 2.65$ at 24 weeks of therapy was a risk factor for developing HCC with an HR of $5.03(p<0.001)$ [32]. We previously demonstrated that the FIB-4 after 1 year of treatment exhibited higher predictive performance for HCC compared with baseline values and that the FIB-4 at 1 year of treatment was an independent predictor of HCC, cirrhotic events, and mortality in compensated cirrhotic patients [33]. Furthermore, we demonstrated that cirrhotic patients with a decline in FIB-4 from baseline to after 1 year of treatment exhibited a significantly lower risk of HCC than did those with an increased FIB-4 [33].

In the present study, we systemically explored the predictive performance of absolute noninvasive fibrosis index values at baseline and after 1 year of treatment and observed changes between these two time points to determine HCC risk in patients with $\mathrm{CHB}$ receiving long-term entecavir therapy. We demonstrated that diabetes mellitus, AFP 12M, FIB-4 12M, and changes in FIB-4 values were independent predictors of HCC for the entire cohort. The APRI and FIB-4 values after 1 year of treatment exhibited higher predictive performance for HCC compared with those at baseline (Tables S2 and S3). Dynamic change in FIB-4 was also an HCC risk predictor. A combination of FIB-4 12M and $\triangle$ FIB-4 provides a convenient algorithm predictive of $\mathrm{HCC}$ risk in patients with $\mathrm{CHB}$ on long-term entecavir therapy. Regardless of baseline liver fibrosis status, the simple algorithm was able to stratify all patients into four subgroups according to the risk of HCC. However, if the cirrhosis status of patients could be ascertained at baseline, the alternative algorithm might provide a more precise estimate of future HCC risk. Of note, the cirrhotic patients with FIB- $412 \mathrm{M} \geq 2.88$ and $\triangle$ FIB- $4 \geq 0$ exhibited a very high risk of HCC (20.9\% at 3 years and $44.4 \%$ at 5 years). By contrast, the noncirrhotic patients with FIB-4 $12 \mathrm{M}<1.58$ or FIB- $412 \mathrm{M} \geq 1.58$ and $\triangle$ FIB- $4<0$ exhibited a very low risk of HCC $(0.3 \%$ at 3 years and $0.6 \%$ at 5 years) (Figure 3 ). Our findings may have implications regarding the prediction of HCC risk in patients with $\mathrm{CHB}$ on long-term NA therapy using noninvasive fibrosis indices. First, the FIB-4 
index after 1 year of treatment may obviate the confounding effect of necroinflammation on the fibrosis measurement and thus better reflect the actual extent of liver fibrosis and predict HCC risk than that at baseline. Second, a decline in FIB-4 values during the first year of entecavir therapy $(75.6 \%$ in the present study) may imply ongoing fibrosis regression in addition to the resolution of necroinflammation and thus represent a favorable predictor for future HCC risk. Instead, an increase in FIB-4 values at 1 year of treatment may indicate fibrosis progression despite NA therapy. The observation that patients with a decline or increase in FIB-4 values during the first year of therapy exhibited an increase or decrease in platelet count at 1 year, respectively, compared to the baseline level, supports this speculation (Table 4). This notion is in agreement with our observation that the noncirrhotic patients with FIB-4 $12 \mathrm{M} \geq 1.58$ and cirrhotic patients with FIB-4 $12 \mathrm{M} \geq$ or $<2.88$ who exhibited an increase in FIB-4 at 1 year of entecavir therapy had a significantly higher risk of HCC compared with their counterparts who had a decline in FIB- 4 at 1 year. The present study provides evidence in support of the relevant role that FIB-4 kinetics during the first year of entecavir therapy may play in predicting future HCC risk. Further research is warranted to elucidate the mechanisms underlying the correlation between on-treatment FIB-4 values and concomitant histological changes.

Our findings may have some clinical implications. First, this was a cohort study with a large patient number that aimed to stratify HCC risk by combining the FIB-4 index and its dynamic change during the first year of NA therapy for the development of a predictive algorithm for clinical application. Second, our simple and inexpensive predictive algorithm exhibited performance comparable to that of the APA-B score but better than that of the PAGE-B, REACH-B, and CU-HCC scores and might help identify a subgroup of noncirrhotic patients with a minimal risk of $\mathrm{HCC}(0.6 \%$ at 5 years), which is lower than those of the low-risk groups identified by the current available risk models and also lower than the threshold for implementing the HCC surveillance $(0.2 \%$ per year) recommended by the AASLD [34,35]. Future efforts may focus on the implementation of additional biomarkers to further identify patients with zero risk of HCC, for whom HCC surveillance might no longer be needed or its interval could be extended. Third, our predictive algorithm likewise helps to identify a subgroup of cirrhotic patients with a very high risk of HCC ( $44.4 \%$ at 5 years), who may require an intensive HCC surveillance program and who represent the optimal candidates for HCC chemoprevention therapy if it becomes available in the near future.

There are also some limitations to note. First, this was a retrospective analysis with a median follow-up period of 4.1 years and only 105 cases of HCC ( $n=12$ in the noncirrhotic patient subgroup). A larger number of patients with a longer follow-up period is required to demonstrate the predictive performance of this algorithm for late HCC development during long-term NA therapy. Second, although we validated our findings by conducting subgroup analyses in cirrhotic patients with liver biopsies and patients receiving 3 or 5 years of continuous entecavir therapy, another cohort of patients is required for the external validation of the predictive performance of the cutoffs we proposed for the FIB-4 index and its change at 1 year of entecavir therapy. The optimal time point for assessing the predictive role of on-treatment FIB-4 changes for the assessment of HCC risk must be further investigated. Third, the severity of liver fibrosis was only assessed using noninvasive fibrosis indices, and the longitudinal changes in these indices during entecavir therapy were not corroborated by elastography or even histological examination. This was because elastography was not an option for us for the majority of the study period and many of the enrolled patients did not provide consent for percutaneous liver biopsy. The implementation of elastography is warranted to improve the performance of the predictive model in the future.

\section{Materials and Methods}

\subsection{Patient Recruitment and Definitions}

Our study was a real-world cohort study with retrospective analysis from two tertiary care medical centres in Taiwan. A total of 1325 NA-naïve patients with CHB who received entecavir 
monotherapy ( $0.5 \mathrm{mg}$ once daily) at China Medical University Hospital $(n=596)$ in Taichung and Kaohsiung Chang Gung Memorial Hospital $(n=729)$ in Kaohsiung were enrolled from January 2007 until August 2012. The inclusion criteria for this cohort included being seropositive for HBsAg for more than 6 months, having an HBV viral load $\geq 2000 \mathrm{IU} / \mathrm{mL}$ at recruitment, and an entecavir treatment duration of more than 12 months. We excluded patients who were NA-experienced ( $n=553)$; had an HBV viral load $<2000 \mathrm{IU} / \mathrm{mL}$ at enrollment $(n=75)$; had HCC at baseline or developed HCC within 1 year of treatment $(n=318)$; had decompensated cirrhosis $(n=49)$; had evidence of autoimmune hepatitis, alcoholic liver disease, or viral coinfections $(n=71)$; had received immunosuppressive therapy $(n=317)$; or had a treatment duration $<12$ months $(n=574)$ [24].

Baseline and on-treatment characteristics and laboratory parameters were collected every 3-6 months during treatment, including age, sex, cirrhosis status, diagnosis of DM, albumin, AST, ALT, total bilirubin, INR, platelet count, AFP, and HBV DNA level.

Noninvasive fibrosis indices, including APRI and FIB-4, were calculated according to the following formulas $[13,14]$ :

$$
\text { APRI }=((\text { AST }[/ \text { ULN] }) /(\text { Platelet count }[109 / \mathrm{L}])) \times 100
$$

Note: The upper limit of normal for AST was $30 \mathrm{U} / \mathrm{L}$.

$$
\text { FIB-4 }=(\text { Age }[\text { years }] \times \text { AST }[\mathrm{U} / \mathrm{L}]) /\left(\text { Platelet count }\left[10^{9} / \mathrm{L}\right] \times \text { ALT }[\mathrm{U} / \mathrm{L}]^{1 / 2}\right)
$$

In addition to the baseline and on-treatment (1 year) index values, the on-treatment changes in index, defined as the index value at 1 year minus the index value at baseline, were calculated. The on-treatment change in index was presented as index $(12 \mathrm{M}-0 \mathrm{M})$ or $\triangle$ index. We defined VR as a serum HBV DNA level of $<50 \mathrm{IU} / \mathrm{mL}$ during entecavir therapy [24]. Abdominal ultrasonography and AFP were performed every 3-6 months during treatment for HCC surveillance as per the National Health Insurance guidelines of Taiwan. Baseline cirrhosis status was confirmed either by liver biopsy $(n=122)$ or abdominal ultrasonography $(n=359)$, which showed consistent findings suggestive of cirrhosis and clinical manifestations, including splenomegaly, gastroesophageal varices, ascites, or thrombocytopenia [36]. HCC was diagnosed with either multiphasic computed tomography (CT) or multiphasic magnetic resonance imaging (MRI) and/or histology according to the practice guidelines of the European Association for the Study of the Liver (EASL) and American Association for the Study of Liver Diseases (AASLD) [34,35]. The presence of DM was ascertained through (1) an HbA1c measurement $\geq 6.5$ percent, (2) a fasting glucose test result $\geq 126 \mathrm{mg}$ per $\mathrm{dL}$, (3) results of two random glucose tests $\geq 200 \mathrm{mg}$ per $\mathrm{dL}$ with classic symptoms of hyperglycemia or a hyperglycemic crisis, (4) a two-hour glucose test result $\geq 200 \mathrm{mg}$ per $\mathrm{dL}$ during an oral glucose tolerance test, or (5) a medical record of anti-diabetic drug use [37].

This study was conducted in accordance with the 1975 Declaration of Helsinki. All patients provided written informed consent, and the study was approved by the research ethics committees of China Medical University Hospital and Chang Gung Memorial Hospital.

\subsection{Statistical Analysis}

For descriptive data, we analysed the categorical variables between the two groups by using the chi-square or Fisher exact test, as applicable. Continuous variables were assessed for normality of distribution by using the Kolmogorov-Smirnov test, and they were non-normally distributed. We used the Mann-Whitney U test to compare the continuous variables, which are expressed as the median \pm interquartile range among the study subgroups. Additionally, we used the receiver operating characteristic (ROC) curve and Youden index to identify the optimal cutoff values for the noninvasive fibrosis indices to differentiate HCC risk. We calculated and listed the sensitivity, specificity, positive predictive value, negative predictive value, and accuracy according to the optimal cutoff values for the APRI and FIB-4 indices (Table S2). We compared the area under the receiver operating characteristics (AUROCs) of APRI and FIB-4 at the different time points to predict HCC 
risk in CHB patients with or without cirrhosis using the DeLong test (Table S3). The comparison of $\triangle \mathrm{APRI}(12 \mathrm{M}-0 \mathrm{M})$ and $\triangle \mathrm{FIB}-4(12 \mathrm{M}-0 \mathrm{M})$ to predict HCC risk by AUROC was also performed in different subgroups (Table S4). Finally, we chose the FIB-4-based model for further analysis because of the following reasons. (1) Both FIB-4 12M and APRI 12M had acceptable AUROCs for predicting HCC in cirrhotic patients and excellent AUROCs in noncirrhotic and all patients. The AUROC of FIB-4 12M was numerically higher than that of APRI 12M (Table S3). (2) The predictive performance of $\triangle$ FIB-4 (12M-0M) for HCC was significantly higher than that of $\triangle$ APRI (12M-0M) for cirrhotic patients and was numerically higher than that of $\triangle \mathrm{APRI}(12 \mathrm{M}-0 \mathrm{M})$ for noncirrhotic patients (Table $\mathrm{S} 4)$. (3) FIB-4 and APRI were used as covariates and were confounding factors according to multivariate Cox regression analysis. Kaplan-Meier analysis with the log-rank test was performed to compare the cumulative HCC incidences among the different subgroups stratified according to FIB-4 $12 \mathrm{M}$ or $\triangle$ FIB-4 $(12 \mathrm{M}-0 \mathrm{M})$ or the combination of FIB-4 $12 \mathrm{M}$ and $\triangle$ FIB-4 $(12 \mathrm{M}-0 \mathrm{M})$. The hazard ratios (HRs) for HCC risk predictors were accessed by univariate and multivariate Cox regression analyses. Stepwise multivariate analysis was performed with the variables with a $p$ value of less than 0.25 in univariate analysis. Multiple imputation was used to deal with missing data for the analysed variables (Supplementary Methods and Table S21) [38,39]. Statistical analyses were performed using SPSS Version 21.0 (Armonk, NY: IBM Corp.) and STATA Version 16. A two-tailed $p$ value of less than 0.05 was considered statistically significant.

\section{Conclusions}

On-treatment changes in FIB-4 and 1-year FIB-4 values are independent predictors of HCC in patients with $\mathrm{CHB}$ receiving long-term entecavir therapy. A combination of these two predictors may help identify patients with noncirrhotic $\mathrm{CHB}$ with the lowest risk of HCC during entecavir therapy.

Supplementary Materials: The following are available online at http://www.mdpi.com/2072-6694/12/5/1177/s1, Table S1: The values of noninvasive fibrosis indices in patients with CHB, Table S2: The sensitivity, specificity, PPV, NPV and accuracy according to the optimal cutoff values of APRI and FIB-4 indices by Youden index in predicting HCC risk, Table S3: Comparison of APRI and FIB-4 at the different time points to predict HCC risk by AUROC in CHB patients with or without cirrhosis, Table S4: Comparison of $\triangle \mathrm{APRI}(12 \mathrm{M}-0 \mathrm{M})$ and $\triangle$ FIB-4 (12M-0M) to predict HCC risk by AUROC in CHB patients with or without cirrhosis, Table S5: Multivariate Cox regression analysis of risk factors (with or without cirrhosis factor) associated with $\mathrm{HCC}$ in patients with $\mathrm{CHB}$, Table S6: Univariate Cox regression analysis of risk factors associated with HCC in patients with noncirrhotic CHB, Table S7: Univariate Cox regression analysis of risk factors associated with HCC in patients with cirrhotic CHB, Table S8: Characteristics of patients with noncirrhotic CHB stratified by $\triangle$ FIB- $4(n=844)$, Table S9: Characteristics of patients with cirrhotic CHB stratified by $\triangle$ FIB- $4(n=481)$, Table S10: Characteristics of all patients with CHB who developed HCC stratified by $\triangle$ FIB- $4(n=105)$, Table S11: Characteristics of patients with cirrhotic CHB who developed HCC stratified by $\triangle$ FIB-4 $(n=93)$, Table S12: Characteristics of patients with noncirrhotic CHB who developed HCC stratified by $\triangle$ FIB-4 $(n=12)$, Table S13: The AUROC, sensitivity, specificity, PPV, NPV and accuracy according to the cutoff values of APRI and FIB-4 indices for predicting HCC risk in cirrhotic patients with liver biopsy, Table S14: Comparison of APRI and FIB-4 at the different time points to predict HCC risk by AUROC in cirrhotic patients with liver biopsy, Table S15: Univariate and multivariate Cox regression analyses of risk factors associated with HCC in histology-verified cirrhotic patients $(n=122)$, Table S16: The AUROCs according to APRI and FIB-4 indices for predicting HCC risk in CHB patients receiving 3 years and 5 years of continuous ETV therapy, Table S17: The sensitivity, specificity, PPV, NPV and accuracy according to the cutoff values of APRI and FIB-4 indices in predicting HCC risk in CHB patients receiving 3 years of continuous entecavir therapy ( $n=1053)$, Table S18: The sensitivity, specificity, PPV, NPV and accuracy according to the cutoff values of APRI and FIB-4 indices in predicting HCC risk in CHB patients receiving 5 years of continuous entecavir therapy $(n=472)$, Table S19: Comparison of PAGE-B, REACH-B, CU-HCC, and APA-B scores and FIB-4-based model by C-statistic and AUROCs to predict HCC risk at 3 and 5 years in patients with CHB receiving entecavir therapy, Table S20. Cumulative incidence of HCC at 2 to 5 years of entecavir therapy in low-risk patients with CHB according to different prediction models, Table S21: Baseline and on-treatment characteristics of patients with CHB before multiple imputation, Figure S1: HCC risk stratification by a combination of FIB- $412 \mathrm{M}$ and $\triangle$ FIB-4 in cirrhotic patients with liver biopsy: - - - Group 1, FIB-4 $12 \mathrm{M}<2.88$ and $\triangle$ FIB-4 $<0$; $\cdots-$ Group 2 FIB-4 $12 \mathrm{M} \geq 2.88$ and $\triangle$ FIB- $4<0$ or FIB-4 $12 \mathrm{M}<2.88$ and $\triangle$ FIB- $4 \geq 0 ;-$ Group 3 FIB-4 $12 \mathrm{M} \geq 2.88$ and $\triangle$ FIB- $4 \geq 0$, Figure S2: HCC risk stratification by a combination of FIB-4 $12 \mathrm{M}$ and $\triangle$ FIB- 4 in (A) all patients treated with entecavir $\geq 3$ years: - - Group 1, FIB-4 $12 \mathrm{M}<2.56$ and $\triangle$ FIB-4 $<0$; $\cdots$ Group 2, FIB-4 $12 \mathrm{M}<2.56$ and $\triangle$ FIB-4 $\geq 0 ; \cdots$ Group 3, FIB-4 $12 \mathrm{M} \geq 2.56$ and $\triangle$ FIB-4 $<0 ;-$ Group 4, FIB-4 $12 \mathrm{M} \geq 2.56$ and $\triangle$ FIB-4 $\geq 0$; (B) noncirrhotic patients treated with entecavir $\geq 3$ years: - - - Group 1, FIB-4 $12 \mathrm{M}<1.58$ and $\triangle$ FIB-4 $<0 ; \cdots$ 
Group 2, FIB-4 $12 \mathrm{M} \geq 1.58$ and $\triangle$ FIB- $4<0$ or FIB-4 $12 \mathrm{M}<1.58$ and $\triangle$ FIB- $4 \geq 0$; — Group 3, FIB-4 $12 \mathrm{M} \geq 1.58$ and $\triangle$ FIB- $4 \geq 0$ and $(\mathrm{C})$ cirrhotic patients treated with entecavir $\geq 3$ years: - - - Group 1, FIB-4 $12 \mathrm{M}<2.88$ and $\triangle$ FIB- $4<0 ; \cdots$ Group 2 FIB-4 $12 \mathrm{M} \geq 2.88$ and $\triangle$ FIB- $4<0$ or FIB-4 $12 \mathrm{M}<2.88$ and $\triangle$ FIB- $4 \geq 0$; Group 3 FIB-4 $12 \mathrm{M} \geq 2.88$ and $\triangle$ FIB- $4 \geq 0$, Supplementary Methods: Details on multiple imputation.

Author Contributions: Concept and design: H.-W.W., C.-Y.P., C.-H.C.; Data acquisition: H.-C.L., W.-P.S., P.-H.C., T.-H.H., S.-N.L., C.-H.H., J.-H.W., M.-H.L., C.-Y.P., C.-H.C.; Manuscript writing: H.-W.W., C.-Y.P.; Statistical analysis: H.-W.W., C.-H.L.; Manuscript supervision: C.-Y.P., C.-H.C. All authors have read and agreed to the published version of the manuscript.

Funding: This research was funded by China Medical University Hospital in Taichung, Taiwan, grant DMR-101-011 and by Chang Gung Memorial Hospital, Taiwan, grants CMRPG8D1181 and CMRPG891481.

Conflicts of Interest: Cheng-Yuan Peng has served as an advisory committee member for AbbVie, BMS, Gilead, and MSD. The coauthors declare no conflict of interest.

\section{References}

1. Perz, J.F.; Armstrong, G.L.; Farrington, L.A.; Hutin, Y.J.; Bell, B.P. The contributions of hepatitis B virus and hepatitis $C$ virus infections to cirrhosis and primary liver cancer worldwide. J. Hepatol. 2006, 45, 529-538. [CrossRef] [PubMed]

2. Chang, T.-T.; Liaw, Y.-F.; Wu, S.-S.; Schiff, E.; Han, K.-H.; Lai, C.; Safadi, R.; Lee, S.S.; Halota, W.; Goodman, Z.; et al. Long-term entecavir therapy results in the reversal of fibrosis/cirrhosis and continued histological improvement in patients with chronic hepatitis B. Hepatology 2010, 52, 886-893. [CrossRef] [PubMed]

3. Hosaka, T.; Suzuki, F.; Kobayashi, M.; Seko, Y.; Kawamura, Y.; Sezaki, H.; Akuta, N.; Suzuki, Y.; Saitoh, S.; Arase, Y.; et al. Long-term entecavir treatment reduces hepatocellular carcinoma incidence in patients with hepatitis B virus infection. Hepatology 2013, 58, 98-107. [CrossRef] [PubMed]

4. Hou, J.; Zhao, W.; Lee, C.; Hann, H.-W.; Peng, C.-Y.; Tanwandee, T.; Morozov, V.; Klinker, H.; Sollano, J.D.; Streinu-Cercel, A.; et al. Outcomes of Long-term Treatment of Chronic HBV Infection with Entecavir or Other Agents From a Randomized Trial in 24 Countries. Clin. Gastroenterol. Hepatol. 2020, 18, 457-467. [CrossRef] [PubMed]

5. Hiramatsu, N.; Yamada, R.; Takehara, T. The suppressive effect of nucleos(t)ide analogue treatment on the incidence of hepatocellular carcinoma in chronic hepatitis B patients. J. Gastroenterol. Hepatol. 2016, 31, 546-552. [CrossRef]

6. Papatheodoridis, G.V.; Sypsa, V.; Dalekos, G.; Yurdaydin, C.; Van Boemmel, F.; Buti, M.; Goulis, J.; Calleja-Panero, J.L.; Chi, H.; Manolakopoulos, S.; et al. Eight-year survival in chronic hepatitis B patients under long-term entecavir or tenofovir therapy is similar to the general population. J. Hepatol. 2018, 68, 1129-1136. [CrossRef]

7. Papatheodoridis, G.V.; Manolakopoulos, S.; Touloumi, G.; Vourli, G.; Raptopoulou-Gigi, M.; Vafiadis-Zoumbouli, I.; Vasileiadis, T.; Mimidis, K.; Gogos, C.; Ketikoglou, I.; et al. Virological suppression does not prevent the development of hepatocellular carcinoma in HBeAg-negative chronic hepatitis B patients with cirrhosis receiving oral antiviral(s) starting with lamivudine monotherapy: Results of the nationwide HEPNET. Greece cohort study. Gut 2011, 60, 1109-1116. [CrossRef]

8. Arends, P.; Sonneveld, M.J.; Zoutendijk, R.; Carey, I.; Brown, A.; Fasano, M.; Mutimer, D.; Deterding, K.; Reijnders, J.G.P.; Oo, Y.H.; et al. Entecavir treatment does not eliminate the risk of hepatocellular carcinoma in chronic hepatitis B: Limited role for risk scores in Caucasians. Gut 2015, 64, 1289-1295. [CrossRef]

9. Wang, H.-W.; Peng, C.-Y.; Lai, H.-C.; Su, W.-P.; Lin, C.-H.; Chuang, P.-H.; Chen, S.-H.; Chen, C.-H.; Hsu, W.-F.; Huang, G.-T. New noninvasive index for predicting liver fibrosis in Asian patients with chronic viral hepatitis. Sci. Rep. 2017, 7, 3259. [CrossRef]

10. Martínez, S.M.; Crespo, G.; Navasa, M.; Forns, X. Noninvasive assessment of liver fibrosis. Hepatology 2011, 53, 325-335. [CrossRef]

11. European Association for Study of the Liver, Asociacion Latinoamericana para el Estudio del H. EASL-ALEH Clinical Practice Guidelines: Non-invasive tests for evaluation of liver disease severity and prognosis. J. Hepatol. 2015, 63, 237-264. [CrossRef] [PubMed]

12. Xiao, G.; Yang, J.; Yan, L. Comparison of diagnostic accuracy of aspartate aminotransferase to platelet ratio index and fibrosis-4 index for detecting liver fibrosis in adult patients with chronic hepatitis B virus infection: A systemic review and meta-analysis. Hepatology 2015, 61, 292-302. [CrossRef] [PubMed] 
13. Wai, C.T.; Greenson, J.K.; Fontana, R.J.; Kalbfleisch, J.D.; Marrero, J.A.; Conjeevaram, H.S.; Lok, A.S. A simple noninvasive index can predict both significant fibrosis and cirrhosis in patients with chronic hepatitis $\mathrm{C}$. Hepatology 2003, 38, 518-526. [CrossRef] [PubMed]

14. Sterling, R.K.; Lissen, E.; Clumeck, N.; Sola, R.; Correa, M.C.; Montaner, J.; Sulkowski, M.S.; Torriani, F.J.; Dieterich, D.T.; Thomas, D.L.; et al. Development of a simple noninvasive index to predict significant fibrosis in patients with HIV/HCV coinfection. Hepatology 2006, 43, 1317-1325. [CrossRef]

15. Nishikawa, H.; Nishijima, N.; Enomoto, H.; Sakamoto, A.; Nasu, A.; Komekado, H.; Nishimura, T.; Kita, R.; Kimura, T.; Iijima, H.; et al. Comparison of FIB-4 index and aspartate aminotransferase to platelet ratio index on carcinogenesis in chronic hepatitis B treated with entecavir. J. Cancer 2017, 8, 152-161. [CrossRef]

16. Kim, J.H.; Kim, J.W.; Seo, J.W.; Choe, W.H.; Kwon, S.Y. Noninvasive tests for fibrosis predict 5-year mortality and hepatocellular carcinoma in patients with chronic hepatitis B. J. Clin. Gastroenterol. 2016, 50, 882-888. [CrossRef]

17. Kim, M.N.; Lee, J.H.; Chon, Y.E.; Ha, Y.; Hwang, S.G. Fibrosis-4, aspartate transaminase-to-platelet ratio index, and gamma-glutamyl transpeptidase-to-platelet ratio for risk assessment of hepatocellular carcinoma in chronic hepatitis B patients: Comparison with liver biopsy. Eur. J. Gastroenterol. Hepatol. 2020, 32, 433-439. [CrossRef]

18. Tseng, T.C.; Liu, C.J.; Su, T.H.; Yang, W.T.; Chen, C.L.; Yang, H.C.; Wang, C.C.; Kuo, S.F.; Liu, C.H.; Chen, P.J.; et al. Fibrosis-4 index helps identify HBV carriers with the lowest risk of hepatocellular carcinoma. Am. J. Gastroenterol. 2017, 112, 1564-1574. [CrossRef]

19. Papatheodoridis, G.; Dalekos, G.; Sypsa, V.; Yurdaydin, C.; Buti, M.; Goulis, J.; Calleja, J.L.; Chi, H.; Manolakopoulos, S.; Mangia, G.; et al. PAGE-B predicts the risk of developing hepatocellular carcinoma in Caucasians with chronic hepatitis B on 5-year antiviral therapy. J. Hepatol. 2016, 64, 800-806. [CrossRef]

20. Papatheodoridis, G.V.; Idilman, R.; Dalekos, G.N.; Buti, M.; Chi, H.; van Boemmel, F.; Calleja, J.L.; Sypsa, V.; Goulis, J.; Manolakopoulos, S.; et al. The risk of hepatocellular carcinoma decreases after the first 5 years of entecavir or tenofovir in Caucasians with chronic hepatitis B. Hepatology. 2017, 66, 1444-1453. [CrossRef]

21. Papatheodoridis, G.V.; Sypsa, V.; Dalekos, G.N.; Yurdaydin, C.; Van Boemmel, F.; Buti, M.; Calleja, J.L.; Chi, H.; Goulis, J.; Manolakopoulos, S.; et al. Hepatocellular carcinoma prediction beyond year 5 of oral therapy in a large cohort of Caucasian patients with chronic hepatitis B. J. Hepatol. 2020. [CrossRef] [PubMed]

22. Wong, V.W.; Chan, S.L.; Mo, F.; Chan, T.C.; Loong, H.H.; Wong, G.L.; Lui, Y.Y.; Chan, A.T.; Sung, J.J.; Yeo, W.; et al. Clinical scoring system to predict hepatocellular carcinoma in chronic hepatitis B carriers. J. Clin. Oncol. 2010, 28, 1660-1665. [CrossRef] [PubMed]

23. Yang, H.I.; Yuen, M.F.; Chan, H.L.; Han, K.H.; Chen, P.J.; Kim, D.Y.; Ahn, S.H.; Chen, C.J.; Wong, V.W.; Seto, W.K.; et al. Risk estimation for hepatocellular carcinoma in chronic hepatitis B (REACH-B): Development and validation of a predictive score. Lancet Oncol. 2011, 12, 568-574. [CrossRef]

24. Chen, C.H.; Lee, C.M.; Lai, H.C.; Hu, T.H.; Su, W.P.; Lu, S.N.; Lin, C.H.; Hung, C.H.; Wang, J.H.; Lee, M.H.; et al. Prediction model of hepatocellular carcinoma risk in Asian patients with chronic hepatitis B treated with entecavir. Oncotarget 2017, 8, 92431-92441. [CrossRef]

25. Hsu, Y.C.; Yip, T.C.; Ho, H.J.; Wong, V.W.; Huang, Y.T.; El-Serag, H.B.; Lee, T.Y.; Wu, M.S.; Lin, J.T.; Wong, G.L.; et al. Development of a scoring system to predict hepatocellular carcinoma in Asians on antivirals for chronic hepatitis B. J. Hepatol. 2018, 69, 278-285. [CrossRef]

26. Yang, H.I.; Yeh, M.L.; Wong, G.L.; Peng, C.Y.; Chen, C.H.; Trinh, H.N.; Cheung, K.S.; Xie, Q.; Su, T.H.; Kozuka, R.; et al. REAL-B (Real-world Effectiveness from the Asia Pacific Rim Liver Consortium for HBV) risk score for the prediction of hepatocellular carcinoma in chronic hepatitis B patients treated with oral antiviral therapy. J. Infect. Dis. 2020, 221, 389-399. [CrossRef]

27. Su, T.H.; Hu, T.H.; Chen, C.Y.; Huang, Y.H.; Chuang, W.L.; Lin, C.C.; Wang, C.C.; Su, W.W.; Chen, M.Y.; Peng, C.Y.; et al. Four-year entecavir therapy reduces hepatocellular carcinoma, cirrhotic events and mortality in chronic hepatitis B patients. Liver Int. 2016, 36, 1755-1764. [CrossRef]

28. Papatheodoridis, G.V.; Dalekos, G.N.; Yurdaydin, C.; Buti, M.; Goulis, J.; Arends, P.; Sypsa, V.; Manolakopoulos, S.; Mangia, G.; Gatselis, N.; et al. Incidence and predictors of hepatocellular carcinoma in Caucasian chronic hepatitis B patients receiving entecavir or tenofovir. J. Hepatol. 2015, 62, 363-370. [CrossRef]

29. Raffetti, E.; Fattovich, G.; Donato, F. Incidence of hepatocellular carcinoma in untreated subjects with chronic hepatitis B: A systematic review and meta-analysis. Liver Int. 2016, 36, 1239-1251. [CrossRef] 
30. Papatheodoridis, G.V.; Manolakopoulos, S.; Touloumi, G.; Nikolopoulou, G.; Raptopoulou-Gigi, M.; Gogos, C.; Vafiadis-Zouboulis, I.; Karamanolis, D.; Chouta, A.; Ilias, A.; et al. Hepatocellular carcinoma risk in HBeAg-negative chronic hepatitis B patients with or without cirrhosis treated with entecavir: HepNet.Greece cohort. J. Viral. Hepat. 2015, 22, 120-127. [CrossRef]

31. Singh, S.; Muir, A.J.; Dieterich, D.T.; Falck-Ytter, Y.T. American Gastroenterological Association Institute technical review on the role of elastography in chronic liver diseases. Gastroenterology 2017, 152, 1544-1577. [CrossRef] [PubMed]

32. Tada, T.; Kumada, T.; Toyoda, H.; Tsuji, K.; Hiraoka, A.; Tanaka, J. Impact of FIB-4 index on hepatocellular carcinoma incidence during nucleos $(\mathrm{t})$ ide analogue therapy in patients with chronic hepatitis B: An analysis using time-dependent receiver operating characteristic. J. Gastroenterol. Hepatol. 2017, 32, 451-458. [CrossRef] [PubMed]

33. Chiang, H.H.; Lee, C.M.; Hu, T.H.; Hung, C.H.; Wang, J.H.; Lu, S.N.; Lai, H.C.; Su, W.P.; Lin, C.H.; Peng, C.Y.; et al. A combination of the on-treatment FIB-4 and alpha-foetoprotein predicts clinical outcomes in cirrhotic patients receiving entecavir. Liver Int. 2018, 38, 1997-2005. [CrossRef] [PubMed]

34. European Association for the Study of the Liver. EASL Clinical Practice Guidelines: Management of hepatocellular carcinoma. J. Hepatol. 2018, 69, 182-236. [CrossRef] [PubMed]

35. Marrero, J.A.; Kulik, L.M.; Sirlin, C.B.; Zhu, A.X.; Finn, R.S.; Abecassis, M.M.; Roberts, L.R.; Heimbach, J.K. Diagnosis, staging, and management of hepatocellular carcinoma: 2018 Practice Guidance by the American Association for the Study of Liver Diseases. Hepatology 2018, 68, 723-750. [CrossRef] [PubMed]

36. Lin, D.Y.; Sheen, I.S.; Chiu, C.T.; Lin, S.M.; Kuo, Y.C.; Liaw, Y.F. Ultrasonographic changes of early liver cirrhosis in chronic hepatitis B: A longitudinal study. J. Clin. Ultrasound 1993, 21, 303-308. [CrossRef]

37. American Diabetes Association. Diagnosis and classification of diabetes mellitus. Diabetes Care 2010, 33, S62-S69. [CrossRef]

38. Rubin, D.B.; Schenker, N. Multiple imputation in health-care databases: An overview and some applications. Stat. Med. 1991, 10, 585-598. [CrossRef]

39. Little, R.J.A.; Rubin, D.B. Statistical Analysis with Missing Data; Wiley: Hoboken, NJ, USA, 2002.

(C) 2020 by the authors. Licensee MDPI, Basel, Switzerland. This article is an open access article distributed under the terms and conditions of the Creative Commons Attribution (CC BY) license (http://creativecommons.org/licenses/by/4.0/). 